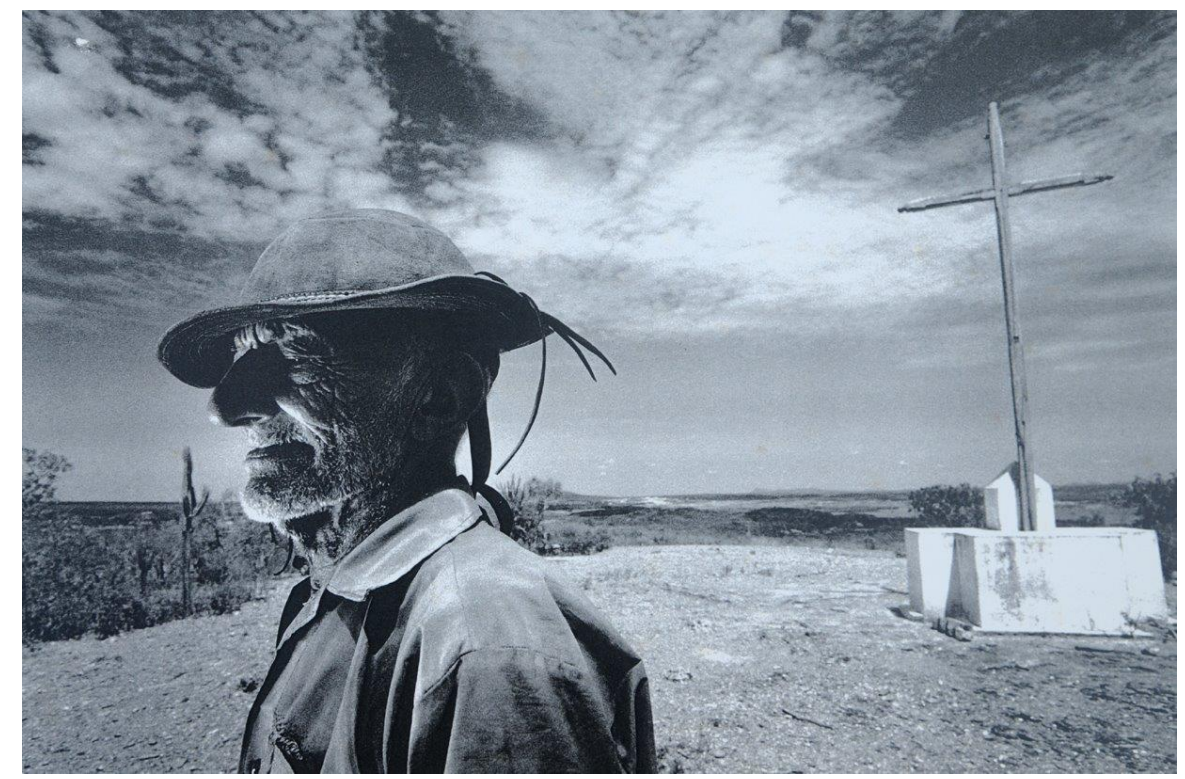

\title{
Revelando o outro: fotojornalismo e representações da pobreza no sertão
}

Revealing the other: photojournalism and representations of poverty in the Brazilian semi-arid

Thiago Manchini de Campos ${ }^{1}$

\section{Resumo:}

Este artigo discorre sobre os usos da fotografia de cunho fotojornalístico voltada para a temática da pobreza no sertão. Parto do pressuposto que, muito mais do que servir como instrumento de denúncia social, a materialidade imagética no contexto do fotojornalismo tem o efeito de reforçar e legitimar os acontecimentos representados ao naturalizar o indivíduo na posiçãosujeito "pobre". O corpus é constituído por imagens de fotojornalistas conhecidos por retratarem a pobreza no sertão brasileiro.

Palavras Chave: Fotografia; Fotojornalismo; Discurso; Pobreza; Sertão

\begin{abstract}
:
This paper discusses the uses of photojournalistic photography focused on the theme of poverty in the brazilian semi-arid. I assume that, more than serving as an instrument of social report, the imagetic materiality in the context of photojournalism has the effect of reinforcing and legitimizing the events represented by naturalizing the individual in the "poor" subject-position. The corpus consists of pictures taken by photojournalists known to portray poverty in the Brazilian backlands.

KeyWords: Photography; Photojournalism; Discourse; Poverty; Semi-arid
\end{abstract}

\footnotetext{
${ }^{1}$ Doutor em Linguística pela UNICAMP. Professor Adjunto I do Curso de Letras da Universidade Federal do Piauí (UFPI). Rua Cícero Eduardo, S/N - Bairro Junco - Picos/PI. Email: thiago.manchini@ufpi.edu.br
} 


\section{Introdução}

O sertão nordestino, mistificado por grandes obras da literatura brasileira, é há algumas décadas alvo do olhar peculiar da fotojornalismo. O evento de captura, tratamento e circulação da imagem tem o efeito, similar ao da literatura, de criar espaços legítimos de interpretação dos possíveis sentidos "do que vem a ser o sertão". Desse modo a fotografia se constitui como um acontecimento que, ao irromper na história, não só formula mas também demanda sentidos. Partimos da constatação já bastante discutida (AUMONT, 2002; DUBOIS, 1993; KRAUSS, 2002; KOSSOY, 2002; SONTAG, 2003, 2004, entre tantos outros) de que a fotojornalismo brasileiro, pautado em uma tradição que atribui às imagens o significado de factualidade instaura, reproduz e legítima um discurso específico sobre a pobreza no sertão sustentado pelas temáticas da falta e religião. Nosso objetivo é abordar o caráter estético desta prática específica do fotojornalismo o qual, dizendo-se "instrumento de denúncia social", autoriza-se a criar uma memória que tem como efeito primordial naturalizar possíveis sentidos para a pobreza, retratando o indivíduo na posição-sujeito "pobre". Este trabalho é fruto de algumas reflexões desenvolvidas em minha tese de doutorado e está dividido em duas partes. Primeiramente, partindo do dispositivo teórico-analítico da Análise de Discurso $(\mathrm{AD})$, iremos pontuar brevemente algumas questões relacionadas à materialidade imagética da fotografia no contexto do fotojornalismo sendo que, no segundo momento, a discussão será expandida de modo a contemplar a análise de algumas imagens produzidas por fotógrafos de renome, conhecidos pelos seus retratos do sertão nordestino.

\section{Abertura do Simbólico: materialidades significantes}

A definição saussuriana de signo como "aquilo que os outros não são", fundamentada na noção de valor, possibilita reflexões que deslocam o foco da tradicional oposição significado/significante, permitindo assim teorizar sobre o político como fator constitutivo da linguagem:

Passamos de uma configuração dicotômica para um espaço de três termos,
em que o linguístico se baseia em uma exclusão. O que vem aqui (...) é a
relação de um signo com um outro signo (...) o valor sustenta e, ao mesmo
tempo, limita o arbitrário (...) Colocar o valor como peça essencial do edifício
equivale a conceber a língua como rede de "diferenças sem termo positivo"
(...) o não dito é constituinte do dizer, porque o todo da língua só existe sob a

2 "Quando se diz que os valores correspondem a conceitos, subentende-se que são puramente diferenciais, definidos não positivamente por seu conteúdo, mas negativamente por suas relações com os outros termos do sistema. Sua característica mais exata é ser o que os outros não são.” (SAUSSURE, 2006, p.136). 
forma não finita do "não-tudo", efeito da alíngua (GADET e PÊCHEUX, 2004, p.58)

Assumir o posicionamento de que a língua - enquanto matéria significante - é política implica deixar de lidar com o sentido por um viés dicotômico para se trabalhar com a contradição e a incompletude, reconhecendo a abertura do simbólico como fato incontornável:

A incompletude é característica do todo processo de significação. A relação pensamento/linguagem/mundo permanece aberta, sendo a interpretação função dessa incompletude, incompletude que consideramos como uma qualidade e não um defeito: a falta, como temos dito em abundância, é também o lugar do possível na linguagem. É isto que chamamos "a abertura do simbólico", à qual juntamos o fato de que a questão do sentido é uma questão que não se fecha pois é uma questão filosófica. (ORLANDI, 2008, p.19)

Apesar da reflexão que concerne à abertura do simbólico ter sido desenvolvida, em um primeiro momento, tendo a língua como objeto, o potencial do trabalho com outras materialidades significantes sempre foi latente. Tal fator se deve primordialmente a uma característica intrínseca ao aparato teórico-analítico da AD: o permitir um olhar privilegiado para o caráter simbólico, não redutivo ao linguístico ${ }^{3}$, do funcionamento discursivo em suas especificidades. De acordo com Lagazzi (2011, p.402)

\begin{abstract}
Não se trata de analisarmos a imagem $e$ a fala $e$ a musicalidade, por exemplo, como acréscimos uma da outra, mas de analisarmos as diferentes materialidades significantes uma no entremeio da outra (...) Em análises com diferentes materialidades é importante que o analista mobilize, na relação teoria-prática, as diferenças materiais, sem que as especificidades de cada materialidade significante sejam desconsideradas, cada uma fazendo trabalhar a incompletude na outra pela contradição.
\end{abstract}

Uma consequência ao se trabalhar com a abertura do simbólico reside na noção de texto promovida por Orlandi, fundamentada na afirmação de que a constituição e formulação do discurso pode ser pensada a partir de dois eixos: o interdiscursivo, de dimensão vertical, e o intradiscursivo, de dimensão horizontal, sendo que todo dizer se dá no cruzamento desses dois eixos. "Sendo atualização da memória discursiva, a formulação se faz materialmente pela colocação do discurso em texto, pela textualização". (ORLANDI, 2008, p.11). Desse modo

\footnotetext{
${ }^{3}$ Por "linguístico" remetemos aqui à noção strictu sensu do termo. É importante mencionar que um dos pontos nevrálgicos na formulação da $\mathrm{AD}$ diz respeito à "inclusão" do sujeito e da história no objeto "língua", questionando assim um dos efeitos do corte saussureano que contempla uma suposta autonomia da mesma. A AD postula que a língua se configura em um sistema de autonomia relativa, sendo que a exterioridade passa, efetivamente, a ser compreendida como parte constituinte do sistema linguístico. Desse ponto de vista não é sustentável conceber uma divisão entre linguístico/extralinguístico face ao objeto discurso.
} 
Quando pensamos o texto pensamos: em sua materialidade (com sua forma, suas marcas e seus vestígios); como historicidade significante e significada (e não como "documento" ou "ilustração"); como parte da relação mais complexa e não coincidente entre memória/discurso/texto; como unidade de análise que mostra acentuadamente a importância de se ter à disposição um dispositivo analítico, compatível com a natureza dessa unidade (...). Não mais como unidade linguística disponível, preexistente, espontânea, naturalizada, mas o texto em sua forma material, como parte de um processo pelo qual se tem acesso indireto à discursividade. (ibid., p12-13).

Cabe então ao analista compreender o texto em sua materialidade, como objeto simbólico e histórico, sendo que é condição para a significação o seu vínculo a determinadas condições de produção. Colocando em outros termos, palavras e imagens não significam em si, e sim porque são dotadas de textualidade, "porque sua interpretação deriva de um discurso que as sustenta, que as provê de realidade significativa." (ibid., p.86). Se para o leitor o texto é a unidade empírica e imaginária produzida por um autor e caracterizada por sequências organizadas de modo "coeso" e "coerente", para o analista é "unidade de análise afetada pelas condições de produção e pela memória (...) lugar da relação com a representação física da linguagem, onde ele é som, letra, espaço, dimensão direcionada, tamanho - material bruto - mas é sobretudo espaço significante" (ibid, p.89). Esta reflexão a nível teórico sinaliza o modo específico no qual a $\mathrm{AD}$ executa o trabalho com o texto e sua materialidade discursiva já que, ao objeto teórico discurso corresponde o domínio analítico texto.

As consequências de se pensar a abertura do simbólico e as materialidades significantes, operacionalizando-as sob a alçada da noção discursiva de texto, são de suma importância para o trabalho com imagens e, em nosso caso específico, com fotografia. Segundo Silva (2004, p.44)

A fotografia enquanto objeto discursivo passa a ser, como todo discurso, atravessada tanto pelas significações estabilizadas quanto pelos deslizes de sentidos, funcionando como linguagem em movimento que tem seus sentidos dependentes do imaginário. A fotografia como objeto de estudos discursivos, constitui-se como um lugar onde há jogos de sentidos, constitui-se como textualidade atravessada por diferentes formações discursivas e pela diversidade de sujeitos.

O fato de abordarmos a fotografia através de um modelo discursivo permite pensar seu funcionamento via a noção de memória discursiva, já que a mesma implica em afirmar que todo e qualquer discurso só é interpretável quando colocado em referência a tal memória: o "antes" e o "alhures" do dito. Do mesmo modo as imagens 
são inscritas em o que podemos denominar de "cultura visual", a qual opera a partir de uma memória visual: o "desde sempre” da imagem.

\section{Memória, Interdiscurso, Formações Discursivas: aparato de análise}

Ao tocar a problemática da imagem Pêcheux (1999, p.55) afirma que essa “encontra assim a análise de discurso por outro viés: não mais a imagem legível na transparência, por que um discurso a atravessa e a constitui, mas a imagem opaca e muda". O primado da opacidade da imagem tem como consequência, no que diz respeito ao seu funcionamento, colocá-la em relação ao processo de significação que é indissociável do interdiscurso. Na passagem do visível ao nomeado a imagem atua como um operador de memória social contendo, nela mesma, um programa ou gesto de leitura. Orlandi (2003, p.15) constata que é nessa memória constitutiva que "os sentidos se estabilizam e se movimentam. Uma coisa ou outra - a estabilização ou a transformação - vai depender da natureza do gesto de interpretação produzido, da posição do sujeito na relação com o interdiscurso". Dessa forma a noção de interdiscurso, definida como "aquilo que fala antes, em outro lugar, independentemente (...) o que chamamos de memória discursiva (...) e que retorna sob a forma do préconstruído" (Pêcheux, 1999, p.31) acaba por assumir uma grande importância ao se pensar a materialidade significante de fotografias em suas especificidades:

\footnotetext{
Tocamos aqui um dos pontos de encontro com a questão da memória como estruturação de materialidade discursiva complexa, estendida em uma dialética da repetição e da regularização: a memória discursiva seria aquilo que, face a um texto que surge como acontecimento a ler, vem restabelecer os "implícitos" (quer dizer, mais tecnicamente, os pré-construídos, elementos citados e relatados, discursos-transversos, etc.) de que sua leitura necessita: a condição do legível em relação ao próprio legível (...) A questão é saber onde residem esses famosos implícitos, que estão "ausentes por sua presença" na leitura da sequência: estão eles disponíveis na memória discursiva como em um fundo de gaveta, um registro oculto? (ibid., p.52)
}

A densidade da fala de Pêcheux contribui para com a construção de um aparato discursivo que dê conta de analisar a materialidade imagética. Primeiramente porque aponta para a noção de pré-construído, intimamente ligada à de interdiscurso, e que age em direção a desestabilizar a oposição entre o exterior e o interior de uma formação discursiva. Em segundo lugar descreve o funcionamento da memória discursiva, com base na repetição que visa a regularização através do que ele nomeia de "implícitos" e, por último, coloca a localização dos "implícitos" face à necessidade de uma sequência. 
Podemos assim propor a construção de um aparato de análise partindo de uma concepção ampla da noção de formação discursivam a qual é em Foucault (2007) definida como a possibilidade de se especificar, entre um determinado número de enunciados caracterizados por um sistema de dispersão, uma regularidade ou regularidades ou seja, encontrar na dispersão de fotos produzidas a partir de diferentes autores, temas, regiões, locais e temporalidades, as regularidades que permitam que sejam classificadas como "imagens da pobreza no sertão". Podemos também pensar na mesma noção a partir de Pêcheux (1988, p.160) que a define como o que pode e deve ser dito - o que pode e deve ser mostrado sobre a pobreza - e que, como consequência, caracteriza as regularidades.

Memória, interdiscurso e a operacionalização da noção de formação discursiva, tomada por um viés amplo, permitem pensar na fotografia - materialidade significante que funciona ao nível do simbólico - como um processo de paráfrase e polissemia (ORLANDI, 1987): entre o dizer "o mesmo" (regularidade) e a ruptura (dispersão), apontando para a possibilidade de outros sentidos, ou seja, que o sentido sempre pode vir a ser outro.

Esta breve exposição leva a outro ponto a se considerar, já que possibilita pensar a imagem, seu funcionamento e efeitos de sentido através da tensão entre o visível e o invisível. Primeiramente, a construção de uma memória através do processo de repetição - paráfrase - do mesmo tema, técnicas, estilo, método, personagens, cenários, ambiente, elementos visuais, etc. que, através da regularização e sistematização produz a relação entre certos indícios que apontam para o que pode e deve ser dito e visto sobre o sertão e a pobreza. Em segundo lugar refletir sobre o caráter polissêmico da linguagem que, via interdiscurso, opera a possibilidade de outros sentidos através da invocação de imagens esquecidas. Uma foto, mesmo que filiada a uma rede de imagens constituídas por paráfrases de si, é única "fala" diferente, desestabilizando em um só movimento a produção de um espaço de interpretação da pobreza no sertão, remetendo a outras imagens, silenciadas, apagadas. As duas ordens - visível/paráfrase/reprodução, invisível/polissêmia/transformação - não se inscrevem em uma lógica dicotômica, sendo exatamente na tensão entre as duas que é possível observar o processo de constituição dos sentidos no discurso imagético. 


\title{
Fotojornalismo e a construção da factualidade da imagem
}

O fotojornalismo ${ }^{4}$, como prática caracterizada por "reportar" e/ou "narrar", foi consolidado na Europa durante o primeiro período pós guerra $(1919$ - 1933). Segundo Guadagnucci $(2010$, p.8) "este é o momento em que a atividade ganha força, pois pela primeira vez na história a fotografia suplantou o texto, que agora aparecia como um complemento da imagem, reduzido a legendas." O surgimento de aparatos menores e mais práticos de captura de imagens ocasionou uma mudança nas convenções da fotografia ao permitir registrar sem ter que recorrer ao ato de posar. Tal deslocamento atribuiu à flagrante importância estética e social, tornando-se o padrão para o fotojornalismo. A popularização da fotografia, atribuída em grande parte à portabilidade da câmera levou, na década de 1950, ao rompimento de fronteiras temáticas e ao desenvolvimento da foto-reportagem, fato que desestabilizou as margens, antes bem delimitadas, da arte e informação. A consequência imediata desta nova práxis levou a que o trabalho de alguns fotógrafos "de imprensa" se confundisse cada vez mais como um modo de expressão artística.

O acontecimento da popularização da fotografia e o desenvolvimento da fotoreportagem potencializaram a "evidência da imagem", que pode ser resumida como o efeito ideológico fundado na ilusão de acesso direto aos fatos sem a mediação do texto escrito. É este efeito de objetividade que fortaleceu a relação da fotografia com o jornalismo. Segundo Mraz (2006),

\begin{abstract}
O fotojornalismo oferece a oportunidade de fazer coincidir os dois polos da fotografia: a informação e a expressividade. Na medida em que esta relação se aproxima do lado informativo, a imagem fica em seu aspecto documental, que é o que acontece no fotojornalismo tradicional. Na medida em que pende para o lado expressivo, converte-se em símbolo, em uma arte descontextualizada. $\mathrm{O}$ melhor fotojornalismo faz coincidir o expressivo e o informativo para criar uma metáfora, uma imagem que contém informação sobre um acontecimento que, ao mesmo tempo, está encarnado com uma força estética para transformá-lo em uma representação de uma referência mais ampla.
\end{abstract}

Mraz menciona que a práxis do fotojornalismo é construída em torno da ilusão de que o fotógrafo não infere no ato fotográfico: o olhar é passivo, limitando-se a

\footnotetext{
${ }^{4} \mathrm{O}$ tema é muito denso para ser abordado aqui. Aos interessados, além dos autores mencionados no início do texto, remeto também a cinco pesquisas desenvolvidas na UNICAMP e que certamente poderão abrir o leque para outras leituras: SÔLHA, H. (1998); SILVA, M. (2004); BODSTEIN, C. (2006); GUADAGNUCCI, J. (2010); CAMPOS, T. M. (2013).
} 
registrar os acontecimentos "tal e qual" o seu desenrolar. Este é um ponto elementar pois, além de legitimar a credibilidade documental da imagem, estrutura também a linguagem desta a partir de "códigos de objetividade" que, em tese, ocultam o efeito causado pela presença do fotojornalista: "O pressuposto de que o descobrimento e a não-interferência dão impulso ao ato fotográfico é particularmente relevante no fotojornalismo, em que a veracidade fotográfica aparentemente transparente combina-se com a suposta objetividade do jornalismo." (ibid.). Schaeffer (1996, p.73) ao comentar sobre a suposta objetividade do fotojornalismo afirma que a "utilização da imagem fotográfica para a transmissão de informações tem estatuto de testemunhos visuais. Aqui, a imagem é com frequência considerada como tendo função de uma "prova" para o conjunto das informações verbais que a acompanham.” A ilusão da objetividade visual potencializa e legitima o modo especifico do fotojornalismo reportar a imagem e o acontecimento: a narrativa. Uma das características principais deste "meio" é a insuficiência da fotografia isolada. A criação do enredo se dá através da sequêncialização de imagens que, em sua "objetividade", constroem o evento e fornecem ao leitor "insights" sobre as circunstâncias do acontecido. Seja a seca no sertão ou a violência nos centros urbanos, a imagem sempre se apresenta como fato: uma imagem vale mais do que mil palavras.

Assim como qualquer materialidade significante, a fotografia tem na interpretação um elemento crucial que aponta para a abertura do simbólico. Desse modo objetividade e narrativa, ao construírem um espaço geográfico, temporal e ideológico de leitura, apresentam-se como efeito de sentido de um determinado discurso fotojjornalístico sobre "o que vem a ser a pobreza no sertão". O fato do discurso ser acontecimento, ancorado a práticas sociais, permite a mobilização de outros gestos de leitura neste espaço de interpretação que, por sua vez, acarreta em deslocamentos e reformulações deste mesmo espaço. Compreender a fotografia e o fotojornalismo por um viés discursivo implica na desestabilização de sentidos - de imagens - que cristalizam e naturalizam na história e no social um lugar para o sujeito.

\section{A estética de algumas representações da pobreza no sertão}

Para a análise foram selecionadas quatro fotografias produzidas por diferentes autores, todos fotojornalistas brasileiros de renome internacional. As imagens circulam em diferentes meios, desde publicações impressas a digitais, e foram todas acessadas via internet, sendo que as legendas mencionam onde as fotografias foram publicadas 
inicialmente. A análise será efetuada em dois momentos: primeiro iremos tratar cada fotografia isoladamente, descrevendo seus elementos visuais/estéticos e discursivos, para depois considerar seu funcionamento a partir da filiação à memória, da paráfrase e polissemia.

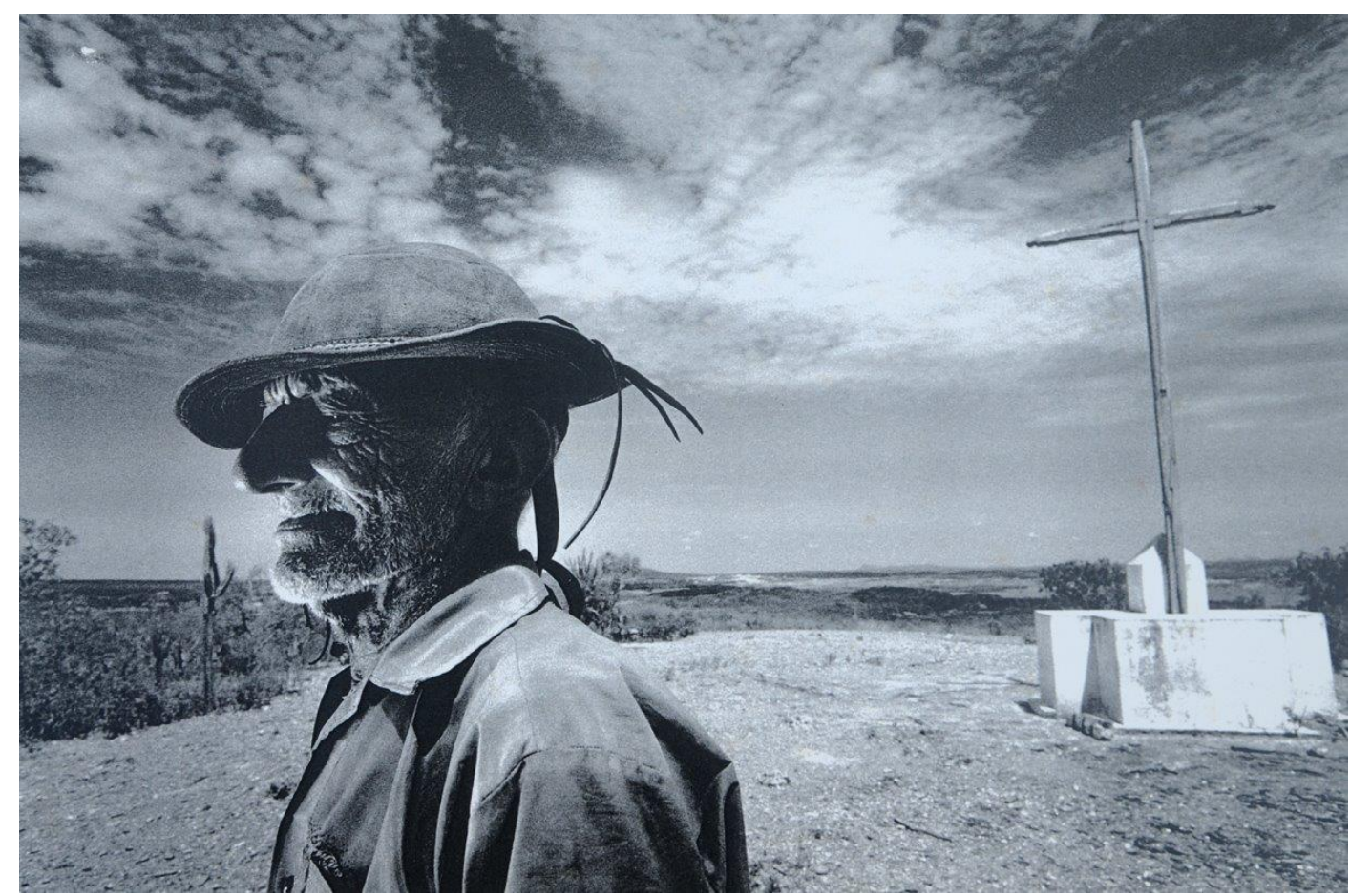

a) Evandro Teixeira “Canudos: 100 anos”, 1997

A primeira fotografia ${ }^{5}$ é da autoria de Evandro Teixeira e foi publicada originalmente em seu livro "Canudos: 100 anos", sendo inclusive a capa do mesmo. O personagem é João de Régis, um dos sobreviventes do massacre de Canudos e que, no momento na fotografia, tinha 110 anos. A imagem em questão é constituída por três planos: no primeiro João de Régis surge em perfil; no segundo plano se encontra uma simples cruz de madeira mas que, em sua proporção, impõe-se ao sujeito da foto; por último, ao fundo, a vastidão do céu e das terras desertas do sertão. Tal tomada de quadro cria um efeito de profundidade que constrói sentidos sobre a vida no sertão: a fé como sendo o elemento sustentador e mediador entre a existência e o nada. O espaço entre João de Régis e a cruz cria um "corredor", uma linha de fuga que conduz o olhar à aparente infinitude do sertão. É interessante notar que, apesar de se encontrar em primeiro plano, a nitidez dos detalhes da face do sujeito retratado pouco nos dizem

\footnotetext{
${ }^{5}$ As informações foram retiradas dos livros onde as fotografias foram publicadas.
} 
dele. Ao nos distanciamos do plano primário a cruz e o cenário ganham proporção. Nesse jogo de foco e perspectiva centraliza-se o sujeito e, em um mesmo movimento, efetiva-se o seu esvaziamento: João de Régis é definido pelos elementos visuais que o cercam: a cruz e o deserto. Na dispersão da composição desta imagem duas regularidades vão se delineando: vazio e religião.

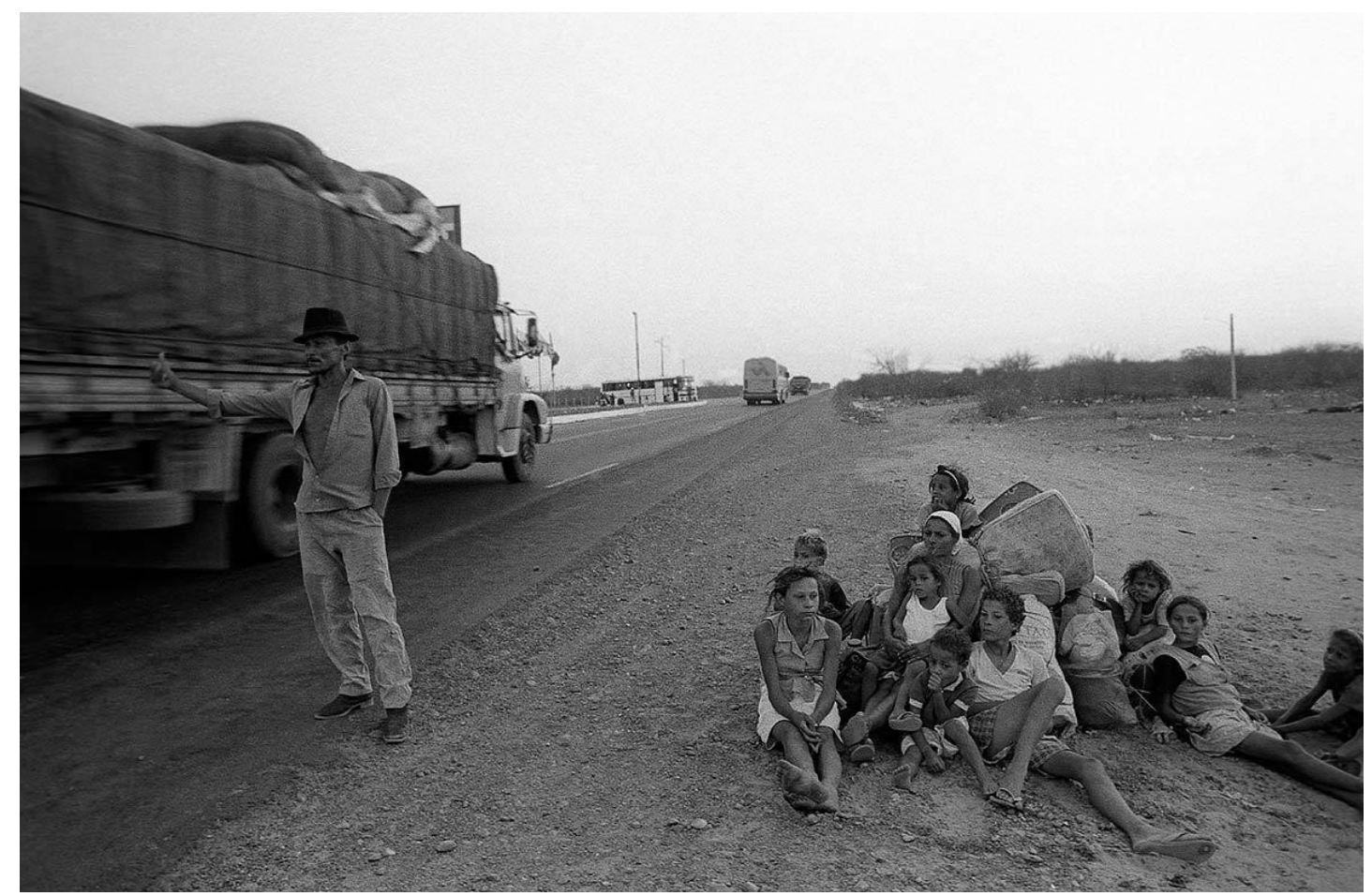

b) Ricardo Funari, reportagem "Seca e Fé no Sertão"

A segunda fotografia, da autoria de Ricardo Funari, retrata uma família do sertão de Pernambuco buscando migrar para São Paulo. Assim como na imagem de "Canudos: 100 anos", esta fotografia também é caracterizada por uma perspectiva profunda, produzida através do mesmo mecanismo. A estrada, paralela ao plano da imagem, funciona como uma linha de fuga que guia e direciona o olhar para o fundo, criando assim um forte contraste entre os planos que compõem a fotografia. É interessante notar que essa linha de fuga é reforçada pelo espaço vazio existente entre o pai e o restante da família, já que é exatamente ai que o olhar se prende e é levado à profundidade da imagem. Ao lado um caminhão surge como elemento levemente desfocado. Este efeito é alcançado ao controlar a velocidade do obturador da câmera (quando maior sua velocidade, menor o tempo de captura). Na imagem em questão o obturador está configurado para registrar a família que, ao contrário dos veículos, encontra-se parada. 
O resultado é uma imagem que captura, no mesmo momento, movimento e ausência deste. Tal recurso retira da família retratada o protagonismo, já que a trajetória do olhar é determinada pela linha que passa ao lado: a estrada imprime movimento, a urbanidade do asfalto que difere do pó do sertão, a aparente passividade e impotência da família que espera contrasta com os automóveis, caminhões e transportes coletivos que ali passam, levando para longe sonhos e esperança.

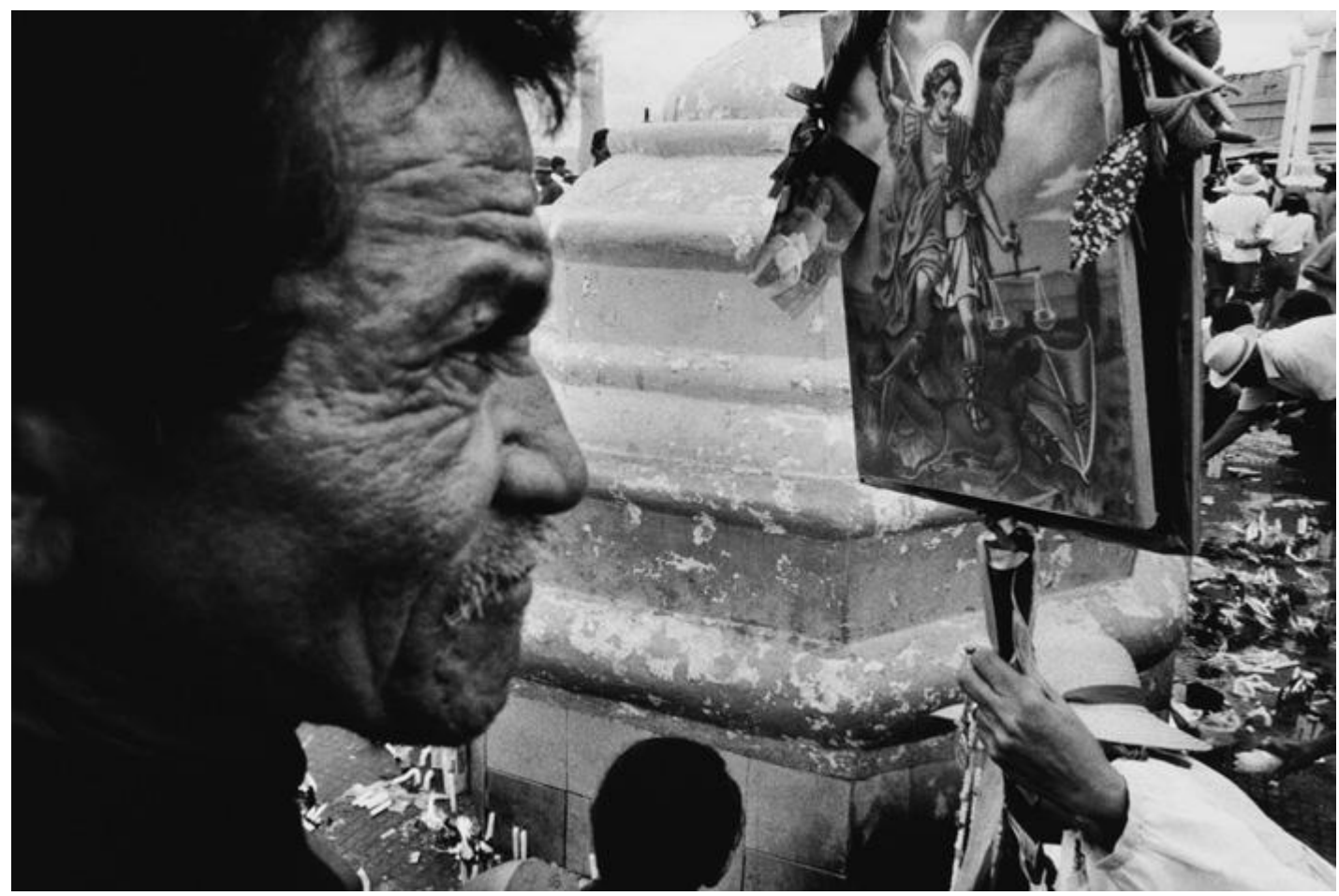

c) Tiago Santana, Coleção “Benditos", 2000

A terceira fotografia é da autoria de Tiago Santana e integra a obra "Benditos". Esta imagem partilha, no âmbito técnico, de um recurso amplamente utilizado por este fotojornalista, a saber, a inserção dos indivíduos retratados no primero plano. Na imagem em questão, similarmente à de João de Régis, o indivíduo é apresentado em perfil porém levemente desfocado e quase fora do quadro, criando um efeito de desproporção entre os planos que compõem a fotografia e imprimindo a ela uma certa medida de profundidade. A imagem é enclausurada, quase que claustrofóbica, sem pontos de fuga: uma face desconhecida que em seu recorte transborda os limites do quadro, algumas velas no chão, pessoas de costas e, ao centro, a gravura de um anjo e um túmulo. A composição desta imagem, apesar de ter sido capturada em um contexto totalmente diferente, compartilha de alguns elementos da capa de "Canudos: 100 anos": o sujeito em perfil compondo o primeiro plano, logo a seguir um elemento que evoca a 
memória da religião e, pouco depois, um último elemento fazendo alusão à falta: a morte. Diferentemente da leitura textual que, no contexto ocidental, ocorre da esquerda para a direita, de cima para baixo, a materialidade da imagem permite e convoca outros modos de "ordenação" e "orientação" da leitura:

Não deslocamos o olhar como na leitura de um texto, da esquerda para a direita e de cima para baixo, por onde a linearidade impõe a lógica do sentido em qualquer forma atualizada de exegese. Para a fotografia, o olhar é deslocado de um ponto fixo, deliberado aleatória e inconscientemente para outras áreas da imagem. Ao retornar invariavelmente para o ponto-referência, um todo se vai re-significando a cada movimento sem que a relação entre as partículas de significação seja unida por laços de causa-efeito. Abandonamos, com esse olhar que remonta a interpretação secular do mundo antes da invenção da escrita, a ordem histórica de nossa existência. O eterno retorno desprende da imagem sua referenciação imediata para remagicizá-la em propriedades fundamentais, contrárias a um "real-dado". (BODSTEIN, 2006, p.170).

O modo como os elementos estão expostos cria um ponto fixo a partir do qual sentidos emergem: entre a vida e a morte surge a fé como mediadora. A falta de enquadramento e o leve desfocar da face em perfil atribuí um sentido de anonimato, cria um espaço que pode ser ocupado por qualquer um já que o sujeito, ao ser recortado e desfocado, perde aquilo que o faz singular.

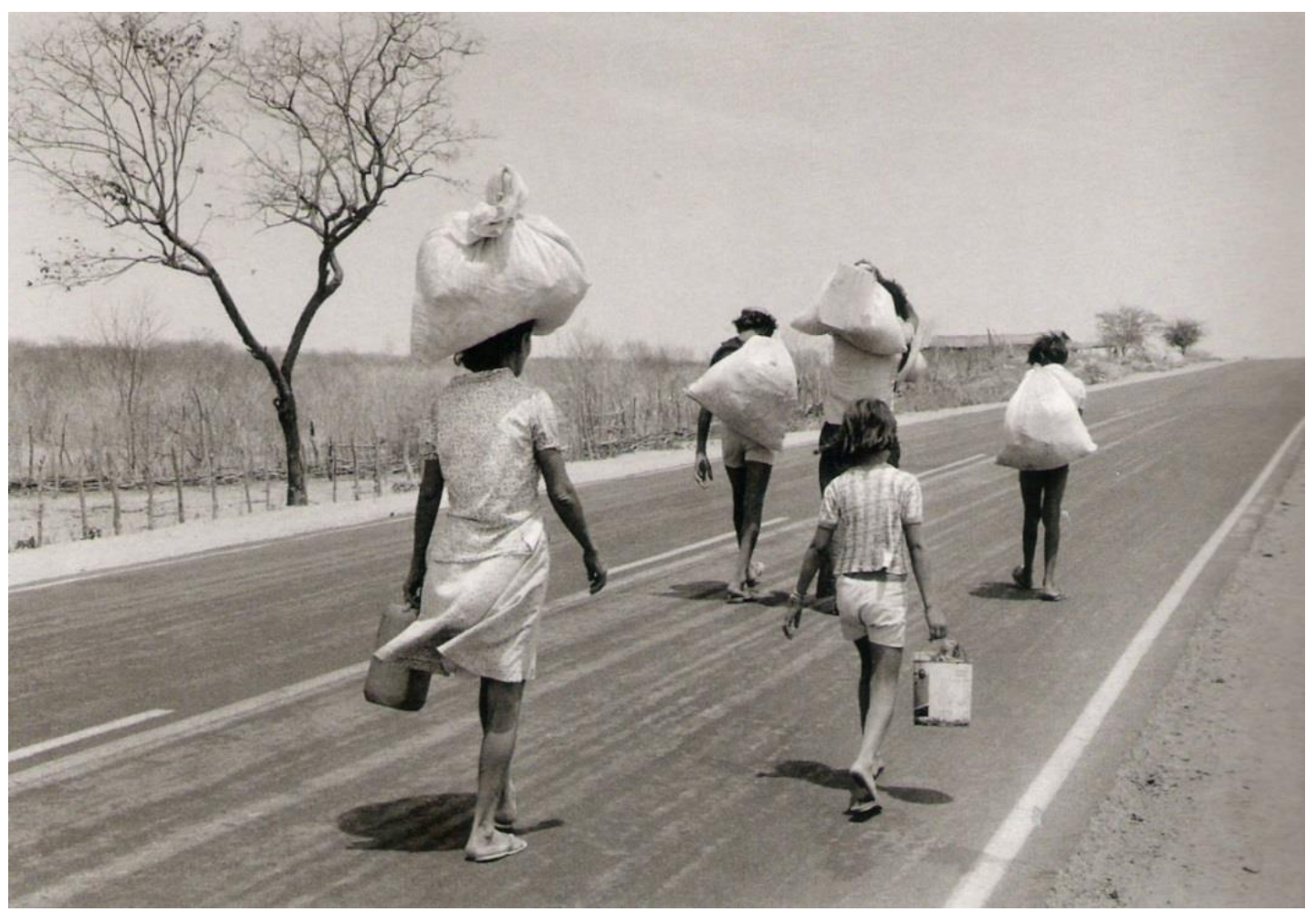

d) Sebastião Salgado, “Terra”, 1997 
A última imagem é da autoria de Sebastião Salgado, sendo publicada inicialmente no livro "Terra". A fotografia, datada de 1983, retrata uma família do sertão cearense buscando fugir da seca. Aqui, assim como na imagem de "Seca e Fé no Sertão", pode-se observar o uso da linha de fuga. O nível e a profundidade do plano são similares, assim como o ângulo da própria linha, mais uma vez delineada pela estrada. É interessante notar que a família é retratada de costas para a imagem, fato que retira a singularidade dos indivíduos aqui representados pois não há faces para os identificar. A amplitude do plano registra um cenário inóspito, deserto, de árvores e arbustos secos, não habitável mas ocupado momentaneamente por indivíduos nômades carregando o pouco que possuem, sem ter onde ficar, à procura para onde ir. Assim como na imagem de "Canudo: 100 anos" a imensidão do sertão, aqui aliada à descaracterização dos personagens, potencializam o efeito de esvaziamento e falta.

\section{Entre a paráfrase a polissemia: memória e espaços de interpretação}

A partilha de técnicas, elementos visuais/estéticos e de um mesmo tema - o sertão - mesmo que de modo abrangente, permite compreender o conjunto de imagens aqui apresentado como filiado a uma rede de memória específica e operando dentro de uma mesma formação discursiva. Há uma constante atualização da memória sobre o que pode e deve ser dito sobre o sertão, sustentada por alguns "implícitos", ou regularidades que vão surgindo ao longo das imagens.

No campo dos elementos visuais chamamos a atenção para a paráfrase que se faz da vastidão do sertão, através da tomada de planos profundos e de linhas de fuga nas fotografias a), b) e d). Apesar de serem imagens que criam e compõem uma narrativa sobre a vida no semi-árido o uso de tal recurso retira, no plano estético e de composição, o protagonismo dos personagens ao colocá-los em desproporção ao cenário: o olhar é guiado para além das vidas retratadas, prendendo-se à imensidão do sertão. É interessante notar que a mesma imensidão é significada como impossibilidade de habitar, sendo somente "ocupada" por sujeitos que buscam sair dali - imagens b) e d). Cria-se assim um efeito de falta que atualiza a memória social relativa ao sertão: um não-lugar distante no tempo.

A segunda paráfrase no plano estético diz respeito a uma temática profundamente enraízada na memória sobre o nordeste e o sertão: a iconografia da religião. As fotografias a) e c), apesar de diferirem entre si no que diz respeito ao espaço e à tomada de perspectiva - a primeira é aberta, a segunda fechada -, têm como 
elemento central representações visuais da fé que atuam como mediadoras entre os sujeitos e a falta, representada pela vastidão do sertão e pela morte. Há todo um roteiro de leitura que atribuí sentidos aos sertanejos, inserindo-os em duas categorias: aqueles sem esperança e em fuga - b), d) - e aqueles que ficam, apegando-se à religião como esperança final $-\mathrm{a}), \mathrm{c})$.

Outra regularidade que marca as imagens é relativa à de-historicização dos indivíduos, efeito do ângulo e distância no qual são retratados. Nas fotos a) e c) são apresentados em perfil, colocados às margens da imagem (em ambos os casos à direita). Apesar de suas faces estarem em primeiro plano, encontram-se "escondidas", seja pelas sombras - a) - seja pela falta de foco e enquadramento - c). Já os indivíduos das fotografias b) e d) estão muito distantes ou de costas, impossibilitando registrar o olhar. Esta é uma questão que abordei em minha tese (CAMPOS, 2013) e que se configura como um elemento comum em muitas imagens produzidas no contexto do fotojornalismo voltado para a temática da pobreza. A falta do olhar é um dos elementos, no processo de atualização da memória, que constituem um espaço de generalização do sujeito-pobre que o torna impessoal. Este mecanismo é facilmente observável nas imagens b) e d), que funcionam como paráfrase uma da outra.

A imagem da autoria de Sebastião Salgado, além de bastante conhecida e de circular em diversos veículos, pré data a de Ricardo Funari. Ambas estão inscritas em uma rede de memória caracterizada por alguns elementos visuais e estéticos que determinam não só a composição da imagem como também delimitam, de certo modo, um plano de leitura, a ponto de serem facilmente intercambiáveis. Podemos trocar uma família por outra e o sentido se mantém, pois o que se busca narrar é o acontecimento (seca, falta, etc.). Repito: o efeito de impessoalidade (ausência de face, do olhar) dehistoriciza o "pobre" e sua condição, podendo este ser o mesmo no interior do Ceará, Pernambuco ou Bahia. Assiste-se a um processo de homogeneização do sertão e dos possíveis sentidos a eles atribuídos já que, se por um lado há a dispersão de personagens, localização geográfica, temporal e de autores, por outro fazem-se presentes as regularidades filiadas à memória de o que é fazer fotojornalismo - presente na paráfrase dos elementos visuais, técnicas e palete de cores - e de o que é ser pobre no sertão - caracterizado pela falta e religião.

Conforme mencionamos anteriormente, a polissêmia é também um fator importante no processo de significação das imagens, já que apesar partilharem de elementos comuns e integrarem de uma mesma formação discursiva, cada imagem tem 
sua especificidade e pode ser "lida" diferentemente. É importante lembrar que o fotojornalismo surge em meio à tensão entre ser um veículo privilegiado de reportargem que, paralelamente, comporta uma certa medida de expressão artística. Desse modo as fotografias em questão podem ser interpretadas como o resultado da prática de reportar as consequências sociais (seca, guerra de canudos, etc.) de eventos localizados em um tempo e espaço definidos; podem também ser tomadas como obra de arte onde o foco é a valorização da estética, tendo como efeito a ficcionalização do registrado. Esta tensão integra o funcionamento discursivo das imagens b) e d) que, se compreendidas como facto, reportam indivíduos com espirito de luta que buscam, na medida do possível, modificar sua condição, significando-os como sujeitos agentes; se tomadas como ficção o sentido é deslocado, sendo que os mesmos indíviduos passam a integrar uma narrativa onde são retratados como sujeitos passivos, totalmente à mercê de uma suposta “cultura” sertaneja que sempre foi e sempre será a mesma ${ }^{6}$.

\section{Revelando o outro}

A discursividade da sequência de fotos aqui apresentada é construída na tensão entre a paráfrase e a polissemia do simbólico, materializada no funcionamento das dispersões e regularidades que caracterizam as formações discursivas, determinando $o$ que pode e deve ser dito. Apesar de cada foto ser única e de sua possibilidade de significação ser aberta, ela também significa perante as outras devido à mesma filiação, criando uma memória sobre a pobreza no sertão e operando um mecanismo de apropriação do outro. Segundo Sontag (2004, p.14)

\footnotetext{
Fotografar é apropriar-se da coisa fotografada. Significa pôr a si mesmo em determinada relação com o mundo, semelhante ao conhecimento - e, portanto, ao poder. (...) O que está escrito sobre uma pessoa ao fato é, declaradamente, uma interpretação, do mesmo modo que as manifestações visuais feitas à mão, como pinturas e desenhos. Imagens fotografadas não parecem manifestações a respeito do mundo, mas sim pedaços dele, miniaturas da realidade que qualquer um pode fazer ou adquirir.
}

A fotografia de cunho documental, no contexto do fotojornalismo, estabelece uma relação voyeurística com o mundo, narrando a realidade por um prisma diferente, aliciador, convincente: “o realismo fotográfico pode ser - e é cada vez mais - definido não como o que "realmente" existe, mas como aquilo que eu "realmente" percebo (...).

\footnotetext{
${ }^{6}$ Em Campos (2013) trabalho a partir da noção de "cultura" voltada para as políticas públicas com a temática da pobreza, mostrando que o discurso destas funciona na tensão entre duas concepções de pobreza: a) fruto de condições históricas e estruturais que estão além do "sujeito-pobre"; b) tendo origem na suposta passividade e conformismo deste mesmo sujeito.
} 
Tudo o que o programa de realismo da fotografia de fato implica é a crença de que a realidade está oculta. E, estando oculta, é algo que deve ser desvelado.” (ibid., p. 136 137). Krauss afirma que aspectos técnicos como o enquadramento funcionam como agente de ruptura com a realidade, algo especifico à materialidade fotográfica:

No interior da imagem, o espaçamento pode nascer do cloisonné, da solarização ou da incorporação de quadros presentes na realidade e destinados a segmentá-la ou a deslocar seus fragmentos. Mas na própria fronteira da imagem, o quadro da máquina fotográfica que corta ou recorta o elemento representado e o separa do contínuo da realidade pode ser considerado como um outro exemplo de espaçamento. Este é o sinal de uma ruptura na experiência instantânea do real, uma ruptura que produz uma sequência. $\mathrm{O}$ enquadramento fotográfico é sempre percebido como uma ruptura no tecido contínuo da realidade. (...) Ao mesmo tempo em que indica esta percepção da realidade, o quadro da máquina fotográfica também a controla e estrutura através da utilização do ponto de vista (...) ou pela escolha do comprimento focal. (2002, p.124)

Para se compreender o funcionamento da materialidade significante da fotografia é necessário considerar tanto sua característica indicial e icônica (que aponta para um referente), como também o processo de construção da representação. Segundo Kossoy (2002, p.22) "trata-se da realidade do documento, da representação: uma segunda realidade, construída (...), mas que é, todavia, o elo material do tempo e espaço representado, pista decisiva para desvendarmos o passado". A teoria sobre a fotografia implica em uma dualidade ontológica que deriva de dois pontos: a fotografia tomada como traço do real, colada ao seu referente - caráter documental - e a fotografia como resultado de um suposto processo "cultural/psicológico" de criação do fotógrafo caráter representacional. Segundo Bodstein (2006, p.103)

O que há de natural na criação de marcas visuais para temas como a fome, a miséria, a discriminação racial ou a expressão de transcendência heroica dessas mazelas, que não sejam controladas pelo fotógrafo, além da luz, tempo de exposição, enquadramento e outras decisões imediatamente pertinentes ao ato fotográfico? (...) De Jacob Riis que, em 1880, sensibilizava a América flagrando gangs de Nova Iorque em seus redutos de penúria, a Eugene Smith cuja série "Country Doctor" tem-se na conta de fundadora de uma expressiva tradição documental que acabou por se revelar imagem dirigida (...) fica evidenciada a escolha de poses. Eugene Smith, inspirador de fotodocumentaristas como Sebastião Salgado, explica (...) que a maioria das histórias fotográficas requerem um certo grau de montagem (re-acomodação e direção cênica que lhe deem uma coerência pictorial e editorial).

Em termos discursivos a realidade do documento resulta da relação material entre o fotógrafo e o fotografado e do modo como a função autor é ocupada. Como sabemos toda posição sujeito é atravessada e determinada por uma memória do dizer e que, em nosso caso específico, delineia um espaço de produção/interpretação da 
imagem, sendo que tal memória é dissimulada através de uma suposta "culturalização" ou "psicologização" do ato fotográfico. Desde modo a hipotética objetividade/neutralidade do fotojornalismo é desconstruída, deixando de ser uma característica fundamental de sua produção pois a descrição, inerente ao ato fotográfico, se configura também como narrativa:

Diante desse quadro, convém perguntar porque apesar de toda esta gama de estudos acerca do estatuto representacional da imagem fotográfica, no fotojornalismo ainda persiste a convenção do instantâneo fotográfico, da foto não posada, como sinônimo de naturalidade e, consequentemente, de realismo (...) o que se considera é a verossimilhança com a realidade, aqui criada através da fotografia. Essa é a lógica do jornalismo. GUADAGNUCCI (2010, p.33)

Há uma inversão na racionalidade: não é o realismo fotográfico que constata fatos, mas sim a narrativa que "cria" o real, sendo que é esse efeito de "real" que encoberta o político e que legitima a fotografia tanto para o autor como para o leitor. $\mathrm{O}$ caráter narrativo da fotografia, no contexto do fotojornalismo, demanda a se considerar o que Susan Sontag chama de "tendência estetizadora da fotografia", isto é, a produção de imagens sobre o real que, conforme já mencionamos, têm a ficcionalização como efeito e que, em última instância, opera uma redução via reificação, isto é, o sujeito da fotografia sempre é um personagem/objeto.

As câmeras miniaturizam a experiência, transformam a história em espetáculo. Assim como criam solidariedade, fotos subtraem solidariedade, distanciam as emoções. O realismo das fotografias cria uma confusão a respeito do real, que é (a longo prazo) moralmente analgésica bem como (a longo e a curto prazo) sensorialmente estimulante. (SONTAG, 2004, p.126).

O funcionamento da materialidade discursiva das fotografias aqui analisadas legitima uma memória de sentidos para a pobreza no sertão, incidindo diretamente ma percepção social das imagens. Através da repetição e regularização via mecanismo de paráfrase, as imagens não só significam como são também re-significadas, construindo nesse processo um roteiro de leitura que remete a outras imagens e materialidades, criando assim um lugar onde se "lê" a pobreza no sertão. A consequência direta deste funcionamento discursivo é a domesticação do olhar, mais especificamente, do olhar ocidental determinando e naturalizando a condição do outro:

A fotografia, que tem tantos usos narcisistas, é também um poderoso instrumento para despersonalizar nossa relação como o mundo; e os dois usos são complementares. Como um par de binóculos sem um lado certo e outro errado, a câmera torna próximas, íntimas, coisas exóticas; e coisas familiares, 
ela torna pequenas, abstratas, estranhas, muito distantes (...). A sensação de estar isento de calamidades estimula o interesse em olhar fotos dolorosas, e olhar para elas sugere e reforça o sentimento de estar a salvo. Em parte isso ocorre porque a pessoa está "aqui" e não "lá", e em parte devido ao caráter de inevitabilidade que todos os fatos adquirem quando transmutados em imagens. No mundo real, algo está acontecendo e ninguém sabe o que vai acontecer. No mundo-imagem, aquilo aconteceu e sempre acontecerá daquela maneira. (ibid. p. 183 - 184).

Por último é interessante observar o funcionamento do clichê no fotojornalismo. De acordo com Pfeiffer (1997, p.37) o clichê produz o efeito de lugar-comum no âmbito verbal, através da repetição das mesmas "fórmulas" ou "regras" de escrita. O mesmo se dá na fotografia:

\begin{abstract}
A fotografia não apenas reproduz o real, recicla-o - um procedimento fundamental numa sociedade moderna. Na forma de imagens fotográficas, coisas e fatos recebem novos usos, destinados a novos significados, que ultrapassam as distinções entre o belo e o feio, o verdadeiro e o falso, o útil e o inútil, bom gosto e mau gosto. Clichês reciclados, tornam-se metaclichês. A reciclagem fotográfica cria clichês a partir de objetos únicos, distintivos; e cria artefatos vívidos a partir de clichês. Imagens de coisas reais são entremeadas com imagens de imagens. (SONTAG, 2004, p.191).
\end{abstract}

Dentro do fotojornalismo o clichê pode ser pensado como o modo no qual se recicla as imagens clássicas da humanidade (cf. CAMPOS, 2013, p. 282-286), sendo que o seu uso não significa, necessariamente, que o clichê se configure como reincidente. Explico: discursivamente a atualização da memória se dá através da repetição do acontecimento o qual, dentro do escopo de nossa discussão, pode se resumir a dois tipos: a) o ato fotográfico como acontecimento; b) a materialidade da fotografia como acontecimento. O clichê opera no nível da paráfrase, uma imagem por outra, porém aberta à polissemia. Este é o ponto essencial que determina se uma imagem é um simples pastiche ou se tem o efeito de trazer algo "novo": é a maior ou menor dissimulação do efeito de clichê que acredito distinguir uma boa imagem de uma banal. Apesar dos fotógrafos aqui mencionados utilizarem o mesmo repertório de técnicas particulares do fotojornalismo - uso da profundidade de campo, linhas de fuga, palete de cores reduzida que possibilita um jogo de luz específico, etc. - sustentando assim o efeito de autoria e de coesão, é relevante notar que o clichê ocorre não somente no âmbito dos aspectos técnicos e iconográficos, operando primordialmente a nível do ideológico, na representação do sertão como falta naturalizada, retratando personagens distantes do $e u$ ocidental e próximos à construção de um outro estranho e exótico. $\mathrm{O}$ cerne do debate da materialidade imagética vai além de uma abordagem ou percepção conteudística das fotografias, estando situado nos efeitos de mostrar/narrar o "pobre" e 
o "sertão". Em última instância, o próprio ato de exibir tem o efeito de distanciar, marginalizar e segregar. Deste modo, o real da fotografia incide na realidade das imagens, atribuindo efeitos de sentido que operam no intermeio da realidade/ficção e, ao fazer isso, significam o sertão como algo que não está aqui, mas está lá. É o avesso da diferença "politicamente correta": a diferença não como modo de compreender o outro, mas como mecanismo de demarcação e marginalização, sinalizando a impossibilidade de um vínculo social.

\section{Conclusão}

É na tensão entre a dispersão e regularidade, paráfrase e polissêmia, fato e ficção, que os dizeres sobre o sertão e pobreza vão sendo construídos. A materialidade das imagens aqui apresentadas é definida por duas memórias que conduzem o olhar. Primeiro a memória da prática do fotojornalismo, que delimita um certo leque e vocabulário de técnicas a serem adotadas; segundo a memória sobre o que é ser pobre no sertão nordestino, filiada a uma rede de discursos verbais e não-verbais que têm na falta e na religião aspectos centrais. No entremeio dessas memórias vai se delineando um espaço de interpretação configurado como narrativa, tendo como efeito principal a naturalização do indivíduo em sua posição sujeito-pobre.

Apesar de compreendermos que a fotografia pode e dever ser utilizada como instrumento de denúncia social, fica latente que há um outro lado da mesma moeda. $\mathrm{O}$ discurso do fotojornalismo - assim como os discursos de outras "instituições" voltadas para a imagem - opera dentro de uma matriz neoliberal, fato que acarreta um golpe nas aspirações "sociais" da fotografia: de modo a circular, imagens de pobreza, violência, catástofres, etc. são tratadas como capital, produto a ser comercializado. Esta seja talvez a grande e principal contradição do fotojornalismo que, ao se apresentar como um modo privilegiado de lutar contra as "injustiças” sociais, contríbui para com a ficcionalização e perpetualização das mesmas.

\section{Referências Bibliográficas}

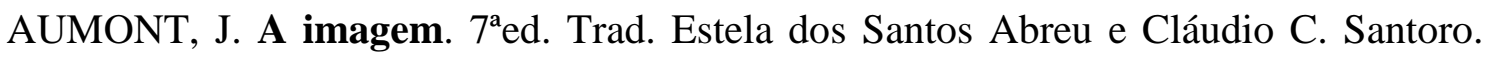
Campinas, SP: Papirus, 2002.

BODSTEIN, C. Fotojornalismo e a ficcionalidade no cotidiano. Tese de Doutorado, IA. UNICAMP. 2006. 
DUBOIS, P. O ato fotográfico e outros ensaios. Trad. Marina Appenzeller. Campinas, SP: Papirus, 1993.

FOUCAULT, M. A Arqueologia do saber. Rio de Janeiro: Forense Universitária, 2007.

GADET, F.; PÊCHEUX, M.. A Língua Inatingível. Trad. Bethania Mariani e Maria Mello. Campinas: Pontes, 2004.

KRAUSS, R. O Fotográfico. Trad. Anne Davée. Barcelona: Editions Macula, 2002.

KOSSOY, B. Realidades e Ficções na Trama Fotográfica. São Paulo: Ateliê Editorial, 2002.

LAGAZZI, S. O recorte e o entremeio: condições para a materialidade significante. In: RODRIGUES, E. SANTOS, G. BRANCO, L. (Orgs.) Análise de Discurso no Brasil: Pensando o Impensado Sempre. Uma Homenagem a Eni Orlandi. Campinas, Editora RG, 2011.

MRAZ, J. A aura de veracidade: Ética e metafísica no fotojornalismo. In: Studium $\mathrm{n}^{\circ} 24.2006$.

ORLANDI, E. A linguagem e seu funcionamento: as formas do discurso. Campinas, SP: Pontes, 1987.

. Ler a cidade: o arquivo e a memória, In: Eni Orlandi (org.). Para uma enciclopédia da cidade. Campinas: Pontes, Labeurb/Nudecri/Unicamp. 2003

Discurso e Texto: Formulação e Circulação dos Sentidos. Campinas: SP: $3^{\text {a }}$ Ed. Pontes Editores, 2008.

PÊCHEUX, M. Semântica e Discurso: uma crítica à afirmação do óbvio. Campinas: Editora da Unicamp, 1988.

Papel da memória. In: ACHARD, P. et al. Papel da memória. Campinas: Editora Pontes, 1999.

SAUSSURE, F. Curso de Lingüística Geral. 27ª ed. São Paulo: Cultrix, 2006.

SCHAEFFER, J-M. A imagem precária: Sobre o dispositivo fotográfico. Trad. Eleonora Bottmann. Campinas:SP: Papirus, 1996.

SILVA, M.G.T. Às bordas do fotográfico e da fotografia, fronteiras tênues. Dissertação de Mestrado, IEL UNICAMP, 2004.

SÔLHA, H. A construção dos olhares: imagem e antropologia visual. Dissertação de Mestrado, IA, UNICAMP. 1998.

SONTAG, S. Diante da dor dos outros. Trad. Rubens Figueiredo. São Paulo: Companhia das Letras, 2003.

das Letras, 2004.

Sobre Fotografia. Trad. Rubens Figueiredo. São Paulo: Companhia 


\section{Para citar essa obra:}

CAMPOS, T. M. Revelando o outro: fotojornalismo e representações da pobreza no sertão. In: RUA [online]. no. 21. Volume 2, p. 201 - 219 - ISSN 1413-2109. Novembro/2015. Consultada no Portal Labeurb - Revista do Laboratório de Estudos Urbanos do Núcleo de Desenvolvimento da Criatividade.

http://www.labeurb.unicamp.br/rua/

Capa: Evandro Teixeira “Canudos: 100 anos”, 1997

Laboratório de Estudos Urbanos - LABEURB

Núcleo de Desenvolvimento da Criatividade - NUDECRI

Universidade Estadual de Campinas - UNICAMP

http://www.labeurb.unicamp.br/

Endereço:

LABEURB - LABORATÓRIO DE ESTUDOS URBANOS

UNICAMP/COCEN / NUDECRI

CAIXA POSTAL 6166

Campinas/SP - Brasil

CEP 13083-892

Fone/ Fax: (19) 3521-7900

Contato: http://www.labeurb.unicamp.br/contato 